\title{
Electrochemical Behaviors of Activated Carbons Prepared from Polymeric Precursor
}

\author{
Soo-Jin Park ${ }^{1, \uparrow}$, Eun-Jung Lee ${ }^{1}$, Byung-Joo Kim² and Young-Seak Lee ${ }^{3}$ \\ ${ }^{1}$ Dept. of Chemistry, Inha Univ., 253 Nam-gu, Incheon 402-751, Korea \\ ${ }^{2}$ Dept. of Green Chemistry \& Environmental Biotechnology, Univ. of Science and Tehcnology, P.O. Box 107, Yuseong, Daejeon 305-600, Korea \\ ${ }^{3}$ Dept. of Fine Chemical Engineering and Chemistry, Chungnam National Univ., 220 Kung-dong, Yuseong, Daejeon 305-764, Korea \\ ^e-mail: sjpark@inha.ac.kr \\ (Received February 15, 2007; Accepted March 20, 2007)
}

\begin{abstract}
In this work, activated carbons (ACs) were prepared from polystyrene-based cation-exchangeable resin (PSI) by a chemical activation with $\mathrm{KOH}$ as an activating agent. The surface morphologies were observed by using SEM, and the textural properties were investigated by using nitrogen adsorption at $77 \mathrm{~K}$. From the experimental results, it was found that the welldeveloped micro- and mesopores were produced by a chemical activation, and the textural properties including specific surface areas and pore volumes were greatly enhanced. The electrochemical behaviors of the ACs showed similar phenomena with that of textural properties. These results indicated that $\mathrm{KOH}$ activation played an important role in the changes of surface, and pore structures, resulting in enhancing the electrochemical properties of the ACs prepared in present work.
\end{abstract}

Keywords : Activated carbons, Adsorption, Activation, Electrochemical behaviors

\section{Introduction}

Activated carbons (ACs) with high specific surface area and pore volumes can be produced from a variety of materials [1]. Activated carbons are important materials that have been used in various industrial applications [2-5]. Recently, investigations on the porous structures and electrochemical behaviors of activated carbons in various forms have been carried out because of their use as electrode materials.

Although a wide range of carbonaceous materials can be converted into ACs, coal and lignocelluloses materials are the most commonly used starting materials for the production of commercial ACs. In addition, many agricultural byproducts, such as nutshells, coconut shells, pecan shells, and peach stones have been found to be suitable precursors. Recently, there have been quite a large number of studies with regard to the preparation of ACs from various polymeric materials because of high carbon yield and low ash content [6-10].

In this work, we prepared activated carbons from polystyrene and investigated their electrochemical properties. In addition, we studied the relation between textural properties such as specific surface area and pore volume, and electrochemical behaviors of the ACs.

Polystyrene (PSI)-based ion-exchangeable resin (SamYang Co., Korea) and potassium hydroxide $(\mathrm{KOH})$ were used as the starting material and chemical agent, respectively. The $\mathrm{KOH}$-impregnated samples were loaded into a horizontal cylindrical furnace (ID $60 \mathrm{~mm}$ ) in a nitrogen atmosphere with a flow rate of $150 \mathrm{ml} / \mathrm{min}$. Activation was carried out by heating the samples at $10^{\circ} \mathrm{C} / \mathrm{min}$ up to $900^{\circ} \mathrm{C}$, and retaining in the furnace for $2 \mathrm{~h}$ at $900^{\circ} \mathrm{C}$. In order to remove residual $\mathrm{K}^{+}$ions, diluted $\mathrm{HCl}$ solution $(0.05 \mathrm{M})$ was used, and then distilled water was also used until $\mathrm{pH}$ became $7.0 \pm 2$. The resulting carbon yield after activation was around $40 \pm 2 \%$.

$\mathrm{N}_{2} / 77 \mathrm{~K}$ adsorption isotherms were determined by using an ASAP 2010 (micromeritics). The amount of $\mathrm{N}_{2}$ adsorbed on the activated carbons was used to calculate the specific surface area by means of the BET equation. The t-plot method of de Boer was used to determine the micropore volume. Before $\mathrm{N}_{2}$ adsorption, the samples were outgassed at $573 \mathrm{~K}$ for $10 \sim 12 \mathrm{~h}$ to obtain a residual pressure less than $1 \times 10^{-6} \mathrm{mmHg}$.

To investigate the electrocatalytic activity of ACs, a linear sweep voltammetry method for a three-electrode cell system was performed. We had prepared a working electrode by coating the ACs mixed with carbon paste onto a glassy carbon electrode. Glassy carbon electrodes ( $3 \mathrm{~mm}$ of diameter, 7.1 $\mathrm{mm}^{2}$ ) served as a substrate for the ACs. The ACs were characterized by stationary current-voltage curves at room temperature in a three-electrode cell. $0.5 \mathrm{M} \mathrm{H}_{2} \mathrm{SO}_{4}$ solution was used as an electrolyte solution. Linear sweep voltammetry was studied by using a potentiostat/galvanostat of AUTOLAB/PGSTAT30 (Eco Chemie, Netherlands). A potential had been changed linearly from $0 \mathrm{mV}$ to $800 \mathrm{mV}$ vs. $\mathrm{Ag}$ / 


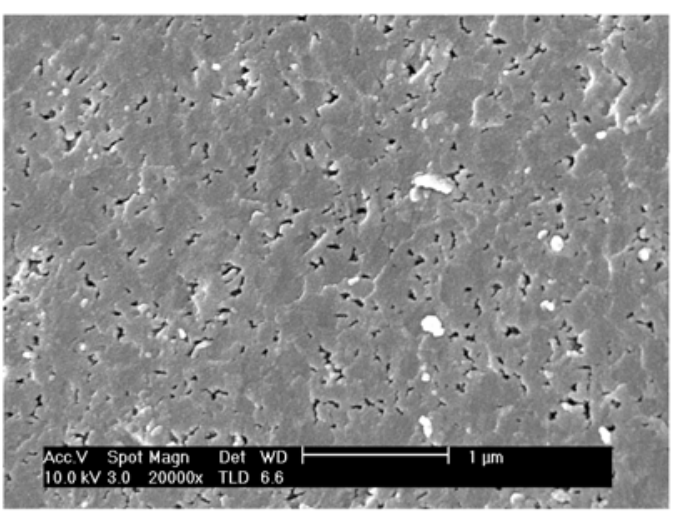

(a)

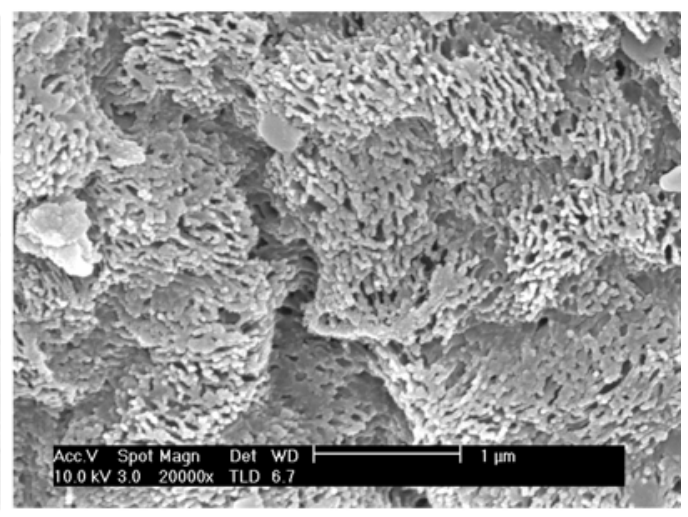

(b)

Fig. 1. SEM photographs of the ACs studied: (a) as-received; (b) activated sample.

$\mathrm{AgCl}$.

The pore structures of the ACs studied were observed by using a scanning electron microscope (SEM). Fig. 1 shows the SEM photographs of the ACs. As shown in Fig. 1, the resulting carbons do have a well-developed pore structure, and the shape of the external surface is significantly changed after the chemical activation.

The nitrogen adsorption isotherms on the ACs studied are shown in Fig. 2. It can be seen that the shape of the adsorption isotherms and the adsorption capacity significantly change after the chemical activation. The adsorption isotherms of the as-received is approximately the Type I isotherm according to BET classification, in which the knees of the isotherms about $\mathrm{P} / \mathrm{P}_{0}=0.01$ are sharp and the plateaus are fairly horizontal. Meanwhile, the activated sample exhibits a more significant increase in adsorption at high relative pressure, in where the knee comes to be more open and rounder and the slope of the plateau increases. And also, nitrogen uptake occurs at high relative pressure $\left(\mathrm{P} / \mathrm{P}_{0}>0.9\right)$. It indicates that

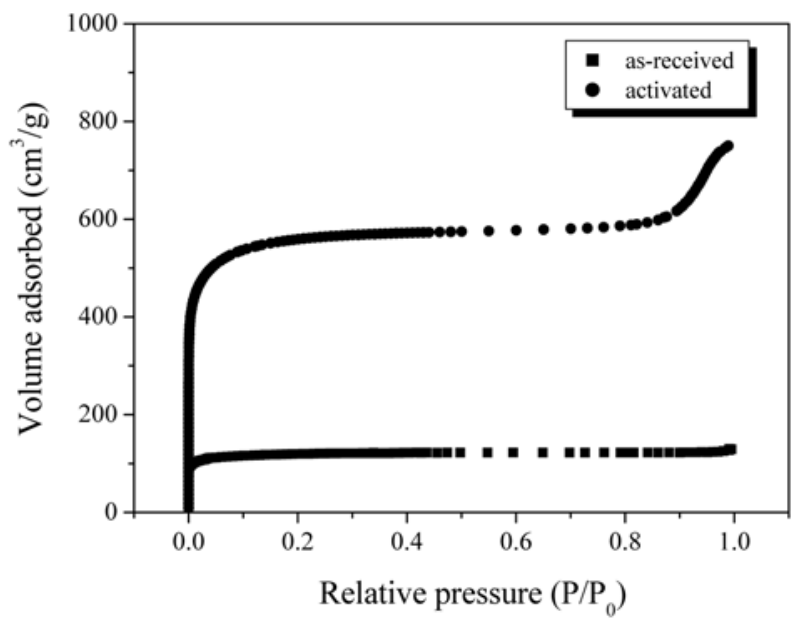

Fig. 2. Nitrogen adsorption isotherms at $77 \mathrm{~K}$ for the ACs studied. the meso- or macropore structure in the sample is significantly developed with the chemical activation due to the occurrence of the widening of the existing micropores [11].

The electrochemical properties of ACs electrodes were studied by a cyclic voltammetry in $0.5 \mathrm{M} \mathrm{H}_{2} \mathrm{SO}_{4}$ of aqueous solution. The typical cyclic voltammograms of the electrode at $10 \mathrm{mV} / \mathrm{s}$ scan rate are shown in Fig. 3. The figures demonstrate that the electrodes are stable in the $0.5 \mathrm{M}$ $\mathrm{H}_{2} \mathrm{SO}_{4}$ aqueous solution within the potential range employed, and the oxidation-reduction reaction was not observed. The total specific capacitance of the ACs was increased after the chemical activation. This result indicates that $\mathrm{KOH}$ activation leads to the development of porous structures of the ACs, resulting in the enhancement of the specific capacitance of the ACs prepared.

In conclusion, the influence of $\mathrm{KOH}$ activation on the textural and electrochemical properties of the ACs synthesized from PSI has been investigated. PSI can be successfully converted into ACs with high porosities. The significant changes in the surface of the ACs occur after the

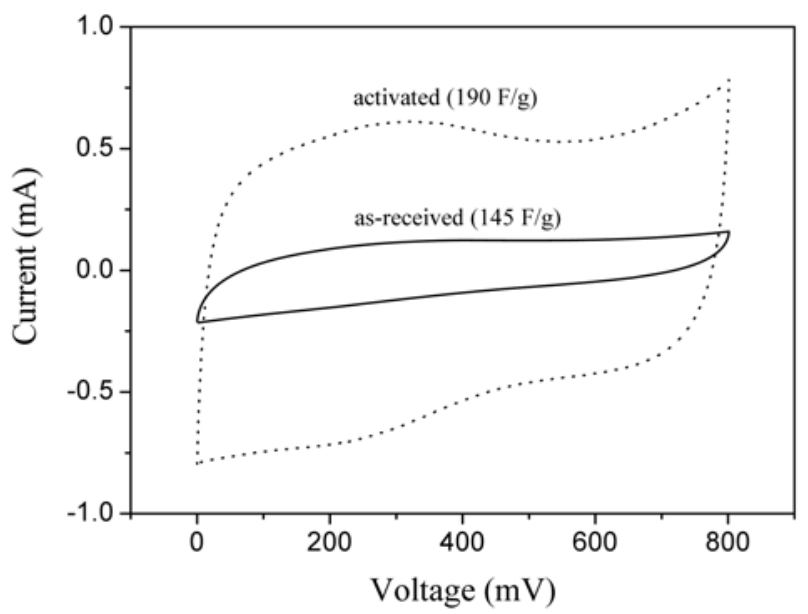

Fig. 3. Diagrams of cyclic voltammetry of the ACs. 
chemical activation. And electrochemical properties of capacitance were also increased after the chemical activation. These results indicated that $\mathrm{KOH}$ played an important role in the changes of surface, pore, and electrochemical properties of ACs during activation.

\section{Acknowledgement}

This paper was performed for the Hydrogen Energy R\&D Center, one of the $21^{\text {st }}$ Century Frontier R\&D Program, funded by the Ministry of Science and Technology of Korea.

\section{References}

[1] Ahmadpour, A.; Do, D. D. Carbon 1997, 35, 1723.
[2] Chi, H. Electrochimi. Acta. 1996, 41, 1633.

[3] Fujimoto, H.; Mabuchi, A.; Tokumitu, K.; Kasuh, T. Carbon 2000, 38, 871.

[4] Wu, F. C.; Tseng, R. L.; Hu, C. C.; Wang, C. C. J. Power Sources 2004, 138, 351.

[5] Park, S. J.; Kim, B. J.; Ryu, S. K. Carbon 1999, 37, 1223.

[6] Marzec, M.; Tryba, B.; Kalenczuk, R. J.; Morawski, A. W. Polym. Adv. Technol. 1999, 10, 588.

[7] Petrov, N.; Budinova, T.; Razvigorova, M.; Ekinci, E.; Yardim, F.; Minkova, V. Carbon 2000, 30, 2069.

[8] Kim, B. J.; Park, S. J. Nanotechnology 2006, 17, 4395.

[9] Cho, K. Y.; Kim, K. J.; Riu, D. H. Carbon Sci. 2006, 7, 271.

[10] Jin, H. Carbon Sci. 2006, 7, 161.

[11] Kim, B. K.; Ryu, S. K.; Kim, B. J.; Park, S. J. J. Ind. Eng. Chem. 2006, 12, 121. 